\title{
Leaf Expansion, Stomatal Conductance, and Transpiration of Vegetable Amaranth (Amaranthus sp.) in Response to Soil Drying
}

\author{
F. Liu and H. Stützel ${ }^{1}$ \\ Institute of Vegetable and Fruit Sciences, University of Hannover, Herrenhäuser Strasse 2, D-30419 \\ Hannover, Germany
}

\begin{abstract}
ADDITIONAL INDEX WORDS. drought, light, leaf area, biomass production
Abstract. This study was designed to quantify the responses of leaf expansion, stomatal conductance, and transpiration of four genotypes of vegetable amaranth [Amaranthus tricolor L. (Hin Choi), A. tricolor L. (Co. 2), A. blitum L. (WS80-192), and A. cruentus L. (RRC 1027)] to soil drying. Two greenhouse experiments were conducted during 1999 and 2000. Soil water status was expressed as the fraction of transpirable soil water (FTSW). Leaf expansion rates, stomatal conductances, and transpiration rates of the stressed plants were determined relative to those of nonstressed plants, and expressed as relative leaf expansion (RLE), relative stomatal conductance (RSC), and relative transpiration (RT), respectively. The rate of soil water extraction differed among genotypes, with RRC 1027 depleting soil water fastest and Hin Choi slowest. Whereas in 1999 all genotypes were equally efficient in soil water use, RRC 1027 extracted a greater volume of transpirable soil water than the other genotypes in 2000. The responses of RLE, RSC, and RT to FTSW were well described by linear-plateau models which allowed calculation of soil-water thresholds for leaf expansion $\left(C_{L}\right)$, stomatal conductance $\left(C_{S}\right)$, and transpiration $\left(C_{T}\right)$. Values for $C_{L}$ were higher than for $C_{S}$ and $C_{T}$. $C_{L}$ was similar for the four genotypes in each year, whereas, $C_{S}$ and $C_{T}$ differed among genotypes. $C_{S}$ and $C_{T}$ was lowest for Hin Choi and highest for WS80-192. Differences of $C_{L}, C_{S}$, and $C_{T}$ between the two experiments might have been due to the different soils used in the experiments and the different evaporative demands during the drought cycles. Under drought stress, the reduction of transpiration of vegetable amaranth was due mainly to reduction of stomatal conductance, not to reduction of leaf expansion. The relative reduction of dry weight caused by drought stress was positively correlated with $C_{S}$ or $C_{T}$ across the four genotypes. Variation in $C_{S}$ and $C_{T}$ among amaranth genotypes revealed different responses to drought stress, which could make them suitable for different drought situations.
\end{abstract}

Leaf area determines light interception and thus influences dry matter production of plants. Similarly, it plays an important role in determining plant water use. Stomata occupy a central position in the pathways for both water loss and $\mathrm{CO}_{2}$ uptake of the plants (Jones, 1998). Under drought stress, plants decrease leaf area and close stomata to control water loss and prevent dehydration of leaf tissue (Blum, 1996). Regulation of leaf expansion and stomatal conductance have been considered to be the main mechanisms by which plants respond to soil water deficits (Jones, 1992; Turner, 1997).

Ritchie (1981) suggested that leaf expansion, photosynthesis, and transpiration showed similar response patterns under drought conditions when compared on the basis of the fraction of transpirable soil water (FTSW) in the root zone. Empirical models describing the dependence of leaf expansion, stomata regulation and transpiration on soil water availability have been developed (Lecoeur and Sinclair, 1996; Ray and Sinclair 1997, 1998; Rosenthal et al., 1987; Sadras et al., 1993a, 1993b; Soltani et al., 2000). These models are based on the assumption that there is a soil-water threshold at which these plant processes in drought-stressed plants start to decrease in relation to well-watered plants. It was observed that the soil-water threshold was higher for leaf expansion than for stomatal regulation and transpiration (reviewed by Sadras and Milroy, 1996). However, since most of the aforementioned studies considered those three plant processes separately, no information is available on the interactive effects of leaf area development and stomatal conductance on transpiration.

Received for publication 12 Sept. 2001. Accepted for publication 23 Apr. 2002. We are grateful to the Lower Saxonian Ministery for Science and Culture for financial support and to the U.S. Department of Agriculture, Agricultural Research Service, North Central Regional Plant Introduction Station, Ames, Iowa, for providing seeds. F. Liu thanks the German Academic Exchange Service (DAAD) for financial support during this research.

'Corresponding author; e-mail Stuetzel@gem.uni-hannover.de.
Amaranths (Amaranthus L. sp.) are protein-rich, annual, herbaceous dicotyledoneous plants of worldwide distribution (Martin and Telek, 1979). Their use as vegetables in tropical agriculture has been well documented (Martin and Ruberte, 1975). Like many $\mathrm{C}_{4}$ crops, amaranths flourish in warm, humid, sunny environments and have lower rates of water loss and greater water use efficiency than $\mathrm{C}_{3}$ plants, especially in dry conditions (Field and Mooney, 1986; Sage and Pearcy, 1987). Therefore, amaranth has often been described as a drought tolerant crop (Myers, 1996; Whitehead and Singh, 1992). However, no quantitative information is available about the responses of leaf expansion, stomatal conductance, and transpiration of these species to soil water deficits. Also, little is known about possible genotypic differences in these traits and their relations to plant performance under drought stress. Therefore, the objectives of this study were to quantify sensitivity of leaf area expansion, stomatal conductance, and transpiration among four genotypes of vegetable amaranth to soil drying and to evaluate the importance of these responses for crop performance during soil drying.

\section{Materials and Methods}

Plant materials and growing Conditions. Experiments were conducted in 1999 and 2000 in a greenhouse of the Institute of Vegetable and Fruit Sciences, University of Hannover, Hannover, Germany. Four genotypes of vegetable amaranth were investigated to cover a wide range of species and origins (Table 1) since no information on drought response was available. Seeds were obtained from the U.S. Department of Agriculture, Agricultural Research Service, North Central Regional Plant Introduction Station, Ames, Iowa.

Pots used were $80 \mathrm{~cm}$ high and $10.5 \mathrm{~cm}$ in diameter and had a volume of 6.9 L. In 1999, they were filled with a loamy sand that contained coarse aggregates whereas in 2000 , the soil was passed 
Table 1. Species, genotype names, origins and the slope $(\mathrm{k})$ of the linear regression analyses of LA against LL x LW of four genotypes of vegetable amaranth used in the two experiments.

\begin{tabular}{|c|c|c|c|}
\hline Species & Genotype name & Origin & $\mathrm{k}$ \\
\hline Amaranthus tricolor L. & Hin Choi & U.S. & 0.68 \\
\hline Amaranthus tricolor L. & Co. 2 & India & 0.61 \\
\hline Amaranthus blitum L. & WS80-192 & Kenya & 0.73 \\
\hline
\end{tabular}

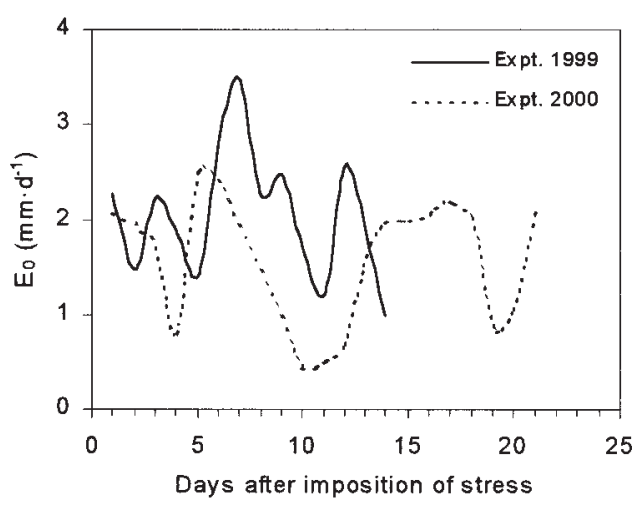

Fig. 1. Evaporative demand $\left(\mathrm{E}_{0}\right)$ during the drying cycle in 1999 and in 2000.

through $1-\mathrm{cm}$ screen to remove large aggregates. The pots were filled with 8.25 (1999) and 8.65 $\mathrm{kg}(2000)$ of soil to a $75 \mathrm{~cm}$ height resulting in a soil density of 1.27 and $1.33 \mathrm{~g} \cdot \mathrm{cm}^{-3}$ in

1999 and 2000, respectively. The soil had a water content of $25 \%$ and $28 \%$ (by volume) at maximum water holding capacity (WHC) in 1999 and 2000, respectively. Four seeds per pot were sown directly on 30 Apr. 1999 and on 31 Mar. 2000. One week after sowing, seedlings were thinned to one plant per pot. Day/night temperature set points were $30 / 20^{\circ} \mathrm{C}$. The day period was calculated daily as the time between sunrise and sunset. The evaporative demand during the drying cycle was recorded from a Class A Pan (Jensen and Middleton, 1970) (Fig. 1). Nutrients were applied with irrigation before the drying cycle at a rate corresponding to $\mathrm{N}, \mathrm{P}$, and $\mathrm{K}$ of 120,39 , and $75 \mathrm{~kg} \cdot \mathrm{ha}^{-1}$, respectively.

To minimize soil evaporation, the soil surface was covered with $4 \mathrm{~cm}$ of quartz gravel. At the beginning of the experiments, pots were water saturated and allowed to drain freely until there was no change in weight. The difference between this weight and soil dry weight (DW) was used to calculate $100 \%$ of water holding capacity (WHC). During the first 3 weeks (four- to six-leaf stage), all pots were irrigated to $90 \%$ of WHC. At treatment initiation, four plants of each genotype were harvested. Thereafter half of the plants were irrigated daily to maintain $90 \% \mathrm{WHC}$ (control) while irrigation was withheld from the remaining plants (stressed) until the transpiration rate was $10 \%$ of the control. Stressed plants were then reirrigated to the level of the control for 1 week. To quantify evaporation through the quartz gravel, four pots covered with gravel but without plants were included. However, evaporation was small in relation to plant transpiration even at $90 \% \mathrm{WHC}$ and was therefore ignored.
Pots were rearranged daily to provide for random distribution in the greenhouse. Throughout the experiments pots were weighed daily at $\approx 1600$ HR to calculate transpiration and soil water content.

Measurements and Calculations. In 1999 and 2000, three and five harvests were conducted, respectively (Table 2). Four plants per treatment were harvested each time. Soil water status in the pots was expressed as the fraction of transpirable soil water (FTSW). Total transpirable soil water (TTSW) was the difference between the pot weights at $100 \%$ WHC and when transpiration rate of the stressed plants decreased to $10 \%$ of the control plants. The daily value of FTSW was estimated as the ratio between the amount of transpirable soil water still remaining in the pot and TTSW:

$\mathrm{FTSW}=\left(\mathrm{WT}_{\mathrm{n}}-\mathrm{WT}_{\mathrm{f}}\right) / \mathrm{TTSW}$

where $\mathrm{WT}_{\mathrm{n}}$ is the pot weight on a given date, and $\mathrm{WT}_{\mathrm{f}}$ is the pot weight at the time when transpiration rate of stressed plants was $10 \%$ of the control plants.

Leaf area (LA) was measured with a leaf area meter(LI-3100; LICOR, Inc., Lincoln, Nebr.). After imposition of drought stress, newly emerging leaves were tagged (leaf number 5, 7, 8 and 9, counted from the base, for Hin Choi, Co. 2, WS80-192, and RRC 1027, respectively). Leaf length (LL) and width (LW) were measured daily. The relationship between the product of $\mathrm{LL} \times \mathrm{LW}$, and LA was determined for each genotype from individual leaf measurements at the harvests. Linear regression of LA vs. LL $\times$ LW was fitted to

$\mathrm{LA}=\mathrm{k} \times \mathrm{LL} \times \mathrm{LW}$

where $\mathrm{k}$ is the slope of the linear function (Table 1).

Daily individual leaf expansion was calculated as the difference between leaf areas on two consecutive days. After imposition of drought stress, stomatal conductance was measured daily in the youngest fully expanded leaves (one leaf per plant, four plants per treatment, nondestructively) from 1100 to 1300 HR with a steadystate porometer (LI-1600; LI-COR, Inc.). Transpiration was calculated as the difference between the current pot weight and that on the previous day.

To minimize day-to-day variation, daily values of leaf area expansion, stomatal conductance, and transpiration of the individual stressed plants were expressed relative to the means of the control plants, yielding relative leaf expansion (RLE), relative

Table 2. Harvest schedule of amaranth genotypes subjected to drying cycles. WHC indicates water holding capacity, and DAS indicates days after imposition of stress

\begin{tabular}{|c|c|c|c|c|c|c|c|c|}
\hline \multirow{2}{*}{$\begin{array}{l}\text { Harvest time according } \\
\text { to soil water status }\end{array}$} & \multicolumn{4}{|c|}{ Expt. 1999 (DAS) } & \multicolumn{4}{|c|}{ Expt. 2000 (DAS) } \\
\hline & Hin Choi & Co. 2 & WS80-192 & RRC 1027 & Hin Choi & Co. 2 & WS80-192 & RRC 1027 \\
\hline Begin of the drying cycle & 0 & 0 & 0 & 0 & 0 & 0 & 0 & 0 \\
\hline $60 \%-70 \%$ of WHC reached ${ }^{\mathrm{z}}$ & & & & & 10 & 7 & 7 & 7 \\
\hline $30 \%-40 \%$ of WHC reached ${ }^{y}$ & & & & & 17 & 14 & 15 & 13 \\
\hline End of the drying cycle & 14 & 11 & 14 & 10 & 21 & 17 & 20 & 17 \\
\hline 7 days after reirrigation & 21 & 18 & 21 & 17 & 28 & 24 & 27 & 24 \\
\hline
\end{tabular}

${ }^{\mathrm{z}}$ Corresponds to FTSW of $\approx 0.5-0.65$.

${ }^{\mathrm{y}}$ Corresponds to FTSW of $\approx 0.15-0.30$. 
stomatal conductance (RSC), and relative transpiration (RT), respectively. The relationships of RLE, RSC, and RT to FTSW for each genotype were evaluated using a linear-plateau model:

RLE, RSC, or RT $= \begin{cases}1 & \text { if } \mathrm{C}_{\mathrm{i}} \leq \mathrm{FTSW} \leq 1 \text { [3a] } \\ 1-\mathrm{A} \times\left(\mathrm{FTSW}-\mathrm{C}_{\mathrm{i}}\right) & \\ \text { if FTSW } \leq \mathrm{C}_{\mathrm{i}} & {[3 \mathrm{~b}]}\end{cases}$

where $A$ is the slope of the linear equation [3b], and $C_{i}$ is the threshold of FTSW at which the measured traits, i.e., RLE, RSC, or RT, start to decline.

DW of the plants (shoot + roots) was determined after ovendrying $\left(48 \mathrm{~h}\right.$ at $50^{\circ} \mathrm{C}$ and $24 \mathrm{~h}$ at $100^{\circ} \mathrm{C}$ ). Relative reduction of DW caused by drought stress was determined as

Relative reduction of $\mathrm{DW}=1-\mathrm{DW}_{\mathrm{s}} / \mathrm{DW}_{\mathrm{w}}$

where $\mathrm{DW}_{\mathrm{s}}$ and $\mathrm{DW}_{\mathrm{w}}$ indicated the average DW of drought-stressed and well-watered plants, respectively.

EXPERIMENTAL DESIGN AND STATISTICAL ANALYSIS. The experiments were arranged in a completely randomized design with four replications. Data were subjected to analysis of variance (ANOVA) procedures (SAS Institute, Inc., 1988). To estimate $A$ and $C_{i}$ in the linear-plateau model [Eq. 3], PROC NLIN of PC SAS (SAS Institute, Inc., 1988) was used. Statistical separations between genotypes were based on comparisons of the coefficients in Eq. [3b] using an unpaired $t$ test. (SAS Institute, Inc., 1988).

\section{Results}

The pattern of soil water extraction in the two experiments was consistent (Fig. 2). FTSW decreased most rapidly in stress treatment pots of RRC 1027 and Co. 2 and most slowly in Hin Choi. In both experiments, the genotypes differed in the number of days to reach the endpoint of the drying cycle (Fig. 2). In 1999, no differences were found in the amount of TTSW held in the pots of the four genotypes. However, in 2000, RRC 1027 extracted the highest amount of transpirable soil water (Table 3).

In both years, at initiation of drought, RRC 1027 had the largest leaf area (Fig. 3), whereas Hin Choi, Co. 2, and WS80-192 had similar leaf areas, which were significantly smaller. Additionally, leaf area of RRC 1027 in both treatments was significantly greater than that of Co. 2 and WS80-192 during the drying period as well as after reirrigation. Leaf area of Hin Choi developed faster and finally surpassed that of RRC 1027 by the end of the drying cycle. At that time, leaf area of the stressed plants was significantly lower than that of the control plants for all genotypes. Stomatal conductance during the first $8 \mathrm{~d}$ of the drying cycle was highest in Co. 2 and lowest in Hin Choi in the stressed plants (Fig. 4).

Response of RLE, RSC, and RT to FTSW were well represented by linear-plateau models (Figs. 5, 6, and 7). For RLE, the relation-

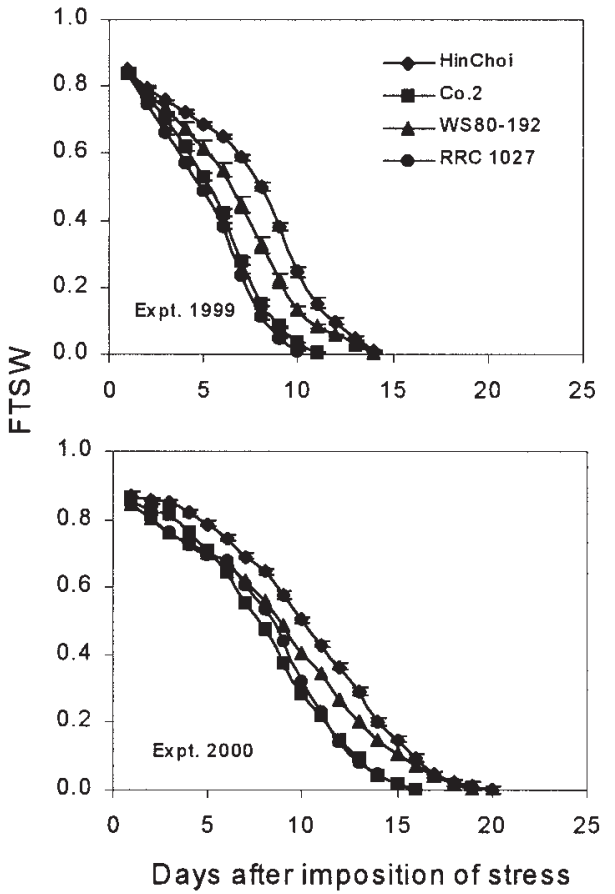

Fig. 2. Trends of the fraction of transpirable soil water (FTSW) in the stressed pots of four genotypes of vegetable amaranth in 1999 and 2000. Vertical bars indicate $\pm 1 \mathrm{SE}(\mathrm{n}=4)$.

ship was almost linear since it started to decrease already when soil was still moist,i.e., atFTSW (averaged over genotypes) of $\approx 0.73$ and $\approx 0.68$ in 1999 and 2000, respectively. No significant genotypic differences were found with respect to $\mathrm{C}_{\mathrm{L}}$ within each year (Table 4). $\mathrm{C}_{\mathrm{L}}$ values of Hin Choi, Co. 2, and WS80-192 were higher in 1999 than in 2000, while $C_{L}$ of RRC 1027 did not differ between the 2 years. Also, RLE of WS80-192 and RRC 1027 declined more sharply and reached zero at larger FTSW than that of Hin Choi and Co. 2. This trend was especially pronounced in 2000. The four genotypes differed in sensitivity of their stomata to soil drying (Fig. 6). $C_{S}$ was highest in WS80-192 and lowest in Hin Choi (Table 4). A positive linear relationship between the relative reduction of DW caused by drought stress and $\mathrm{C}_{\mathrm{S}}$ for the four genotypes was found (Fig. 8).

For all genotypes in both experiments, RT was not affected until FTSW decreased to $\approx 0.5$ to 0.2 (Table 4 , Fig. 7 ). In each year, the four genotypes differed in $\mathrm{C}_{\mathrm{T}}$. Even though for each genotype the $\mathrm{C}_{\mathrm{T}}$ value differed between the 2 years, the order of the four genotypes was unchanged. In both years, $\mathrm{C}_{\mathrm{T}}$ was lowest in Hin Choi and highest in WS80-192. Moreover, $\mathrm{C}_{\mathrm{T}}$ was positively related to the relative reduction of DW caused by drought stress (Fig. 8).

\section{Discussion}

This study was designed to evaluate the importance of individual physiological traits as part of different adaptive strategies to drought used by different amaranth genotypes. Therefore, the effects of soil water deficits on leaf expansion, stomatal conductance, and transpiration in four genotypes of vegetable amaranth were quantified using data from two pot experiments conducted in a temperature controlled greenhouse. Even though the amount of soil per pot was

Table 3. Soil water content at FTSW $=0$ and the amount of the transpirable soil water (TTSW) held in the pots of four genotypes of vegetable amaranth.

\begin{tabular}{lcccc}
\hline \hline & \multicolumn{2}{c}{$\begin{array}{c}\text { Soil water content } \\
(\text { vol. \%) } \pm \text { SE at FTSW }=0\end{array}$} & \multicolumn{2}{c}{ TTSW (g) \pm SE } \\
\cline { 2 - 3 } Genotype & Expt. 1999 & Expt. 2000 & Expt. 1999 & $1343 \mathrm{a} \pm 19$ \\
Hin Choi & $3.9 \mathrm{a}^{\mathrm{z}} \pm 0.4$ & $5.2 \mathrm{a} \pm 0.3$ & $1329 \mathrm{a} \pm 32$ & $1476 \mathrm{a} \pm 25$ \\
Co. 2 & $4.3 \mathrm{a} \pm 0.5$ & $5.5 \mathrm{a} \pm 0.4$ & $1338 \mathrm{a} \pm 22$ & $1461 \mathrm{a} \pm 26$ \\
WS80-192 & $3.9 \mathrm{a} \pm 0.4$ & $5.4 \mathrm{a} \pm 0.3$ & $1326 \mathrm{a} \pm 12$ & $1542 \mathrm{~b} \pm 8$ \\
RRC 1027 & $4.4 \mathrm{a} \pm 0.4$ & $4.5 \mathrm{~b} \pm 0.3$ & &
\end{tabular}

${ }^{\mathrm{z}}$ Mean separation $(\mathrm{n}=4)$ within columns by $t$ test at $\left.P \leq 0.05\right)$. 

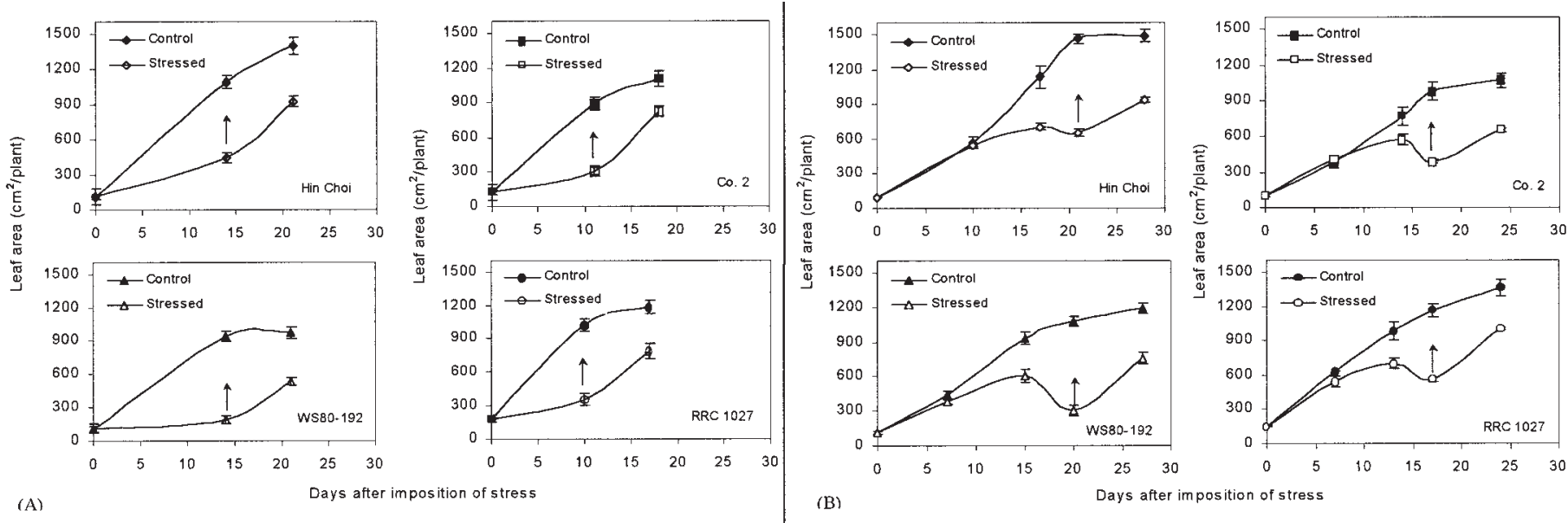

(A)

Fig. 3. Leaf area per plant of four genotypes of vegetable amaranth during stress and after reirrigation in (A) Expt. 1999 and (B) Expt. 2000. Arrows indicate reirrigation. Vertical bars indicate \pm 1 SE $(n=4)$.

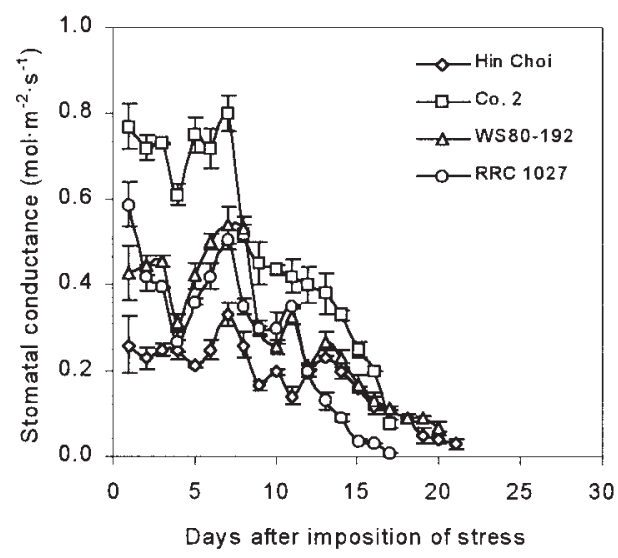

the pots was similar for the four genotypes in each year. This indicates that FTSW as defined in our study is a reproducible indicator of soil water status, despite many uncertainties in determining FTSW as discussed elsewhere (Sadras and Milroy, 1996).

Responses of leaf expansion, stomatal conductance, and transpiration to soil water deficit could be described successfully by linearplateau models. Linear-plateau models were able to distinguish genotypes withrespect to their physiological responses toadrying soil in other studies (Ray and Sinclair, 1997; Rosenthal et al., 1987). The virtue of these models is that they allow definition of critical soil water contents at which physiological processes start to decline.

The $C_{L}$ values of $\approx 0.7$ obtained herein for vegetable amaranth are higher than the average of 0.61 reported by Sadras and Milroy (1996) across numerous species, growing conditions, and methods. They are, however, comparable to those of potato (Solanum tuberosum L.) (0.73, Jefferies, 1993) and barley (Hordeum vulgare L.) (0.66, Milroy and Goyne, 1995). Compared to leaf expansion, stomatal conductance and transpiration were less sensitive to soil water deficit. $C_{S}$ values ranging between 0.35 and 0.60 were consistent with values reported for other crops, i.e., sunflower (Helianthus annuus L.) (0.40, Tardieu and Davies, 1993) and cauliflower [Brassica oleracea L.(Botrytis Group)] (0.47 to 0.66 , Kochler, 2000). The $\mathrm{C}_{\mathrm{T}}$ values of amaranth genotypes were similar to the values obtained from maize (Zea mays $\mathrm{L}$.) cultivars $(0.39$ to 0.60, Ray and Sinclair, 1997) and chickpeas (Cicer
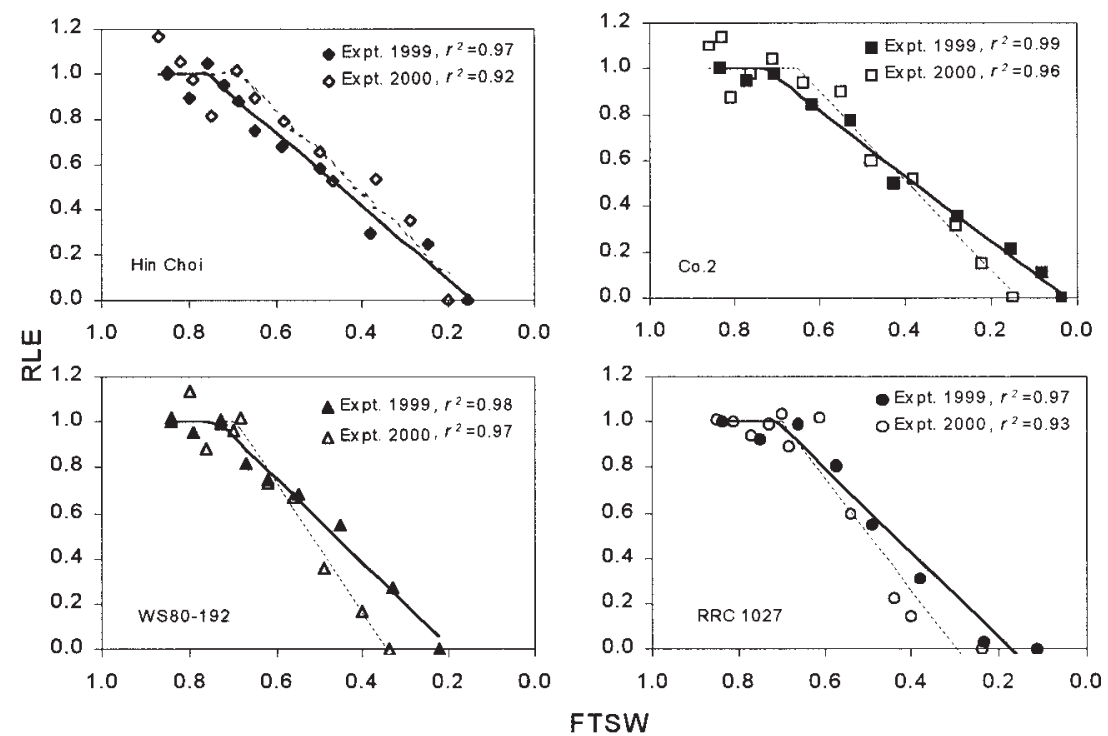

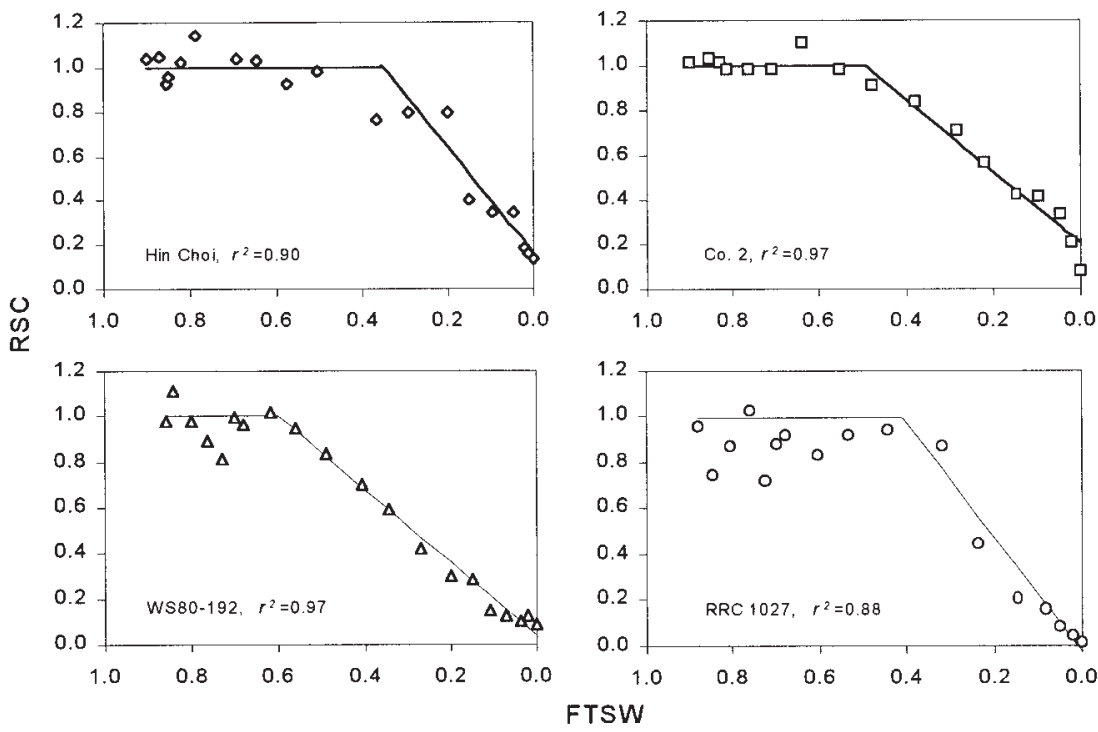

influence of root signals, water conductivity in the soil, and evaporative demand on transpiration.

Similar to other observations (Sadras and Milroy, 1996), $C_{L}$ in vegetable amaranths was greater than $C_{T}$, i.e., transpiration still continues at soil water contents at which leaf area is already reduced. This could be interpreted as an increase in specific transpiration between $\mathrm{C}_{\mathrm{L}}$ and $\mathrm{C}_{\mathrm{T}}$. However, transpiration was based on the whole plant and is dependent on light interception (Sadras et al., 1993b). Thus, the effect of leaf area reduction on transpiration is fairly small at the beginning of a drought situation. Also, the similarity of the values of $C_{S}$ and $C_{T}$ indicates that the reduction of transpiration was due mainly to a reduction of stomatal conductance but not a reduction of leaf area.

Variation in the pattern of soil water extraction and the susceptibility of stomata to soil drying among the four genotypes indicates different strategies of these genotypes to cope with drought stress. RRC 1027 and

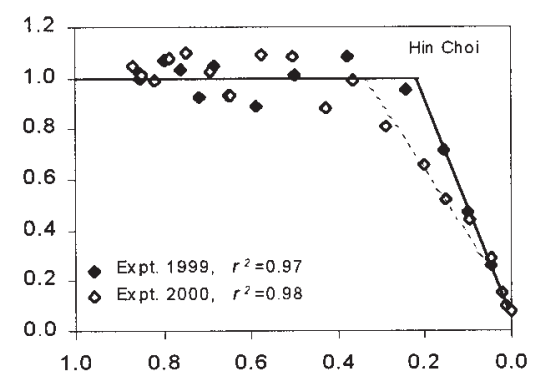

$\stackrel{\vdash}{\propto}$
Fig. 6. Relationship between the fraction of transpirable soil water (FTSW) and relative stomatal conductance (RSC) of four genotypes of vegetable amaranth. Symbols are measured data and curves were fitted by using linear-plateau model (Eq. [3]).
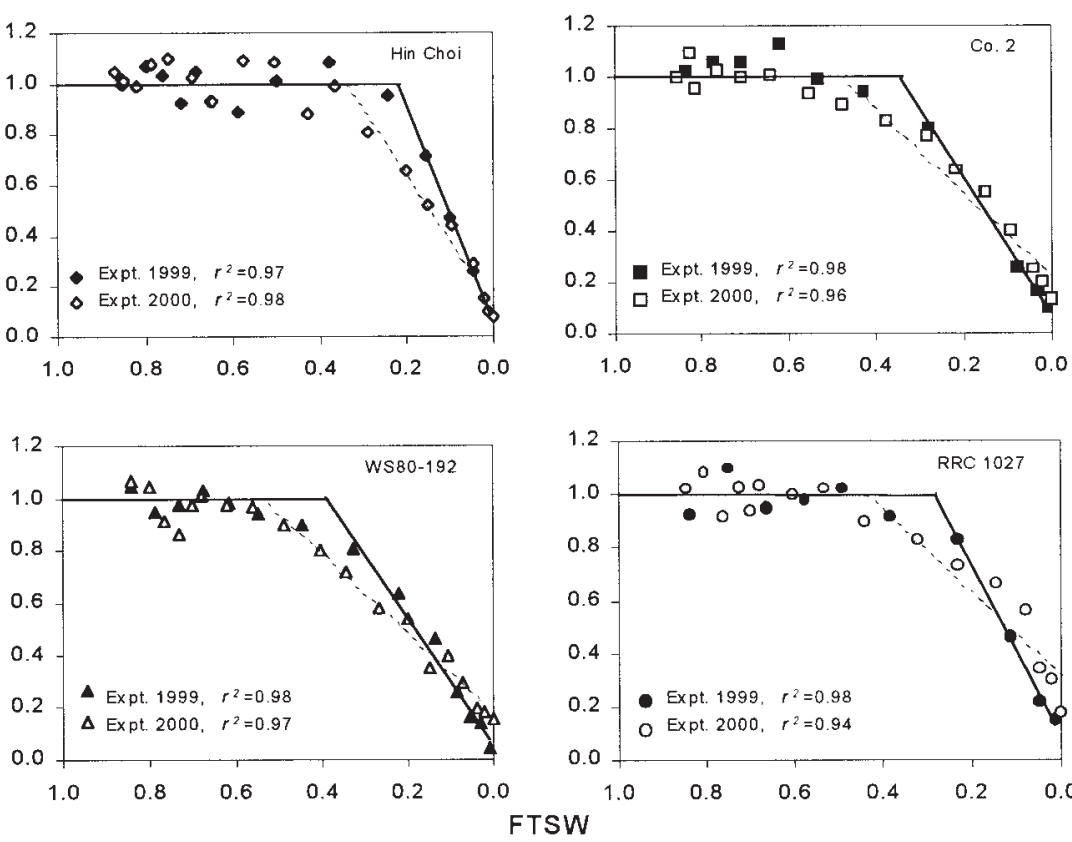

Co. 2 extracted soil water fastest among the four genotypes and were expected to grow faster than Hin Choi and WS80-192 since they had higher water use efficiencies than the other two genotypes (Liu, 2000). RRC 1027 and Co. 2 can be characterized as water-spenders (Blum, 1996; Turner, 1997). However, the reasons that contributed to the fast use of soil water differed between them. RRC 1027 was characterized by rapid leaf area development, whereas Co. 2 exhibited high stomatal conductance. As plants in drought prone areas are often planted after the start of the rainy season at high soil moisture content, features securing rapid root and shoot growth after germination (early vigor) will ensure that most of the available soil water can be used by the plants. Such features of drought resistance have been recognized previously in wheat (Turner and Nicolas, 1987). Thus, RRC 1027 and Co. 2 appear to be suitable for cultivation in regions where the rainy season and dry season are clearly distinguished. They could be planted when soil water is available and abundant and attain high yield before the dry season commences.

In contrast, Hin Choi and WS80-192 can both be classified as water savers although they pursue different strategies for saving water. Hin Choi had low stomatal conductance even under well-watered conditions, which resulted in a longer period of soil water extraction. This trait has been considered to be benefi-

Fig. 7. Relationship between the fraction of transpirable soil water (FTSW) and the relative transpiration rate (RT) of four genotypes of vegetable amaranth. Symbols are measured data and curves are fitted by using linear-plateau model (Eq. [3]).

cial in regions where crops have to produce their yield primarily on water stored in the soil (Passioura, 1972). Also, a later closure of stomata by Hin Choi under drought stress allowed the plants to maintain a high rate of photosynthesis for a longer period of time,

Table 4. Thresholds $\mathrm{C}_{\mathrm{L}}, \mathrm{C}_{\mathrm{S}}$, and $\mathrm{C}_{\mathrm{T}}$ for relative leaf expansion (RLE), relative stomatal conductance (RSC), or relative transpiration (RT), respectively, for four genotypes of vegetable amaranth grown in 1999 and 2000. Thresholds are expressed as the fraction of transpirable soil water (FTSW) below which RLE, RSC, and RT decrease in comparison to well-watered plants. For details see Eq. [3].

\begin{tabular}{|c|c|c|c|c|c|}
\hline Genotype & \multicolumn{2}{|c|}{$\mathrm{C}_{\mathrm{L}} \pm \mathrm{SE}$} & $\frac{\mathrm{C}_{\mathrm{S}} \pm \mathrm{SE}}{2000}$ & \multicolumn{2}{|c|}{$\mathrm{C}_{\mathrm{L}} \pm \mathrm{SE}$} \\
\hline Hin Choi & $0.77 \pm 0.02$ & $0.69 \pm 0.03$ & $0.35 \pm 0.05$ & $0.22 \pm 0.02$ & $0.34 \pm 0.02$ \\
\hline WS80-192 & $0.74 \pm 0.02$ & $0.69 \pm 0.02$ & $0.60 \pm 0.03$ & $0.39 \pm 0.02$ & $0.53 \pm 0.03$ \\
\hline RRC 1027 & $0.70 \pm 0.03$ & $0.67 \pm 0.03$ & $0.42 \pm 0.06$ & $0.28 \pm 0.02$ & $0.44 \pm 0.04$ \\
\hline
\end{tabular}




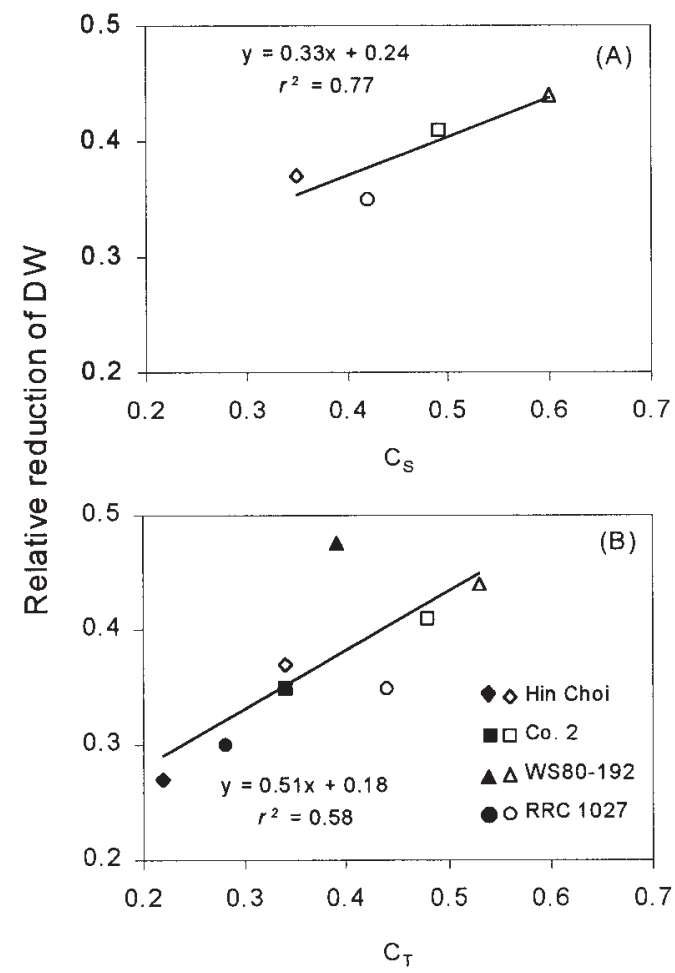

Fig. 8. Relationship between the relative reduction of dry weight (DW) and the (A) soil water thresholds of stomatal conductance $\left(\mathrm{C}_{\mathrm{S}}\right)$ and $(\mathbf{B})$ soil water thresholds of transpiration $\left(\mathrm{C}_{\mathrm{T}}\right)$ for four genotypes of vegetable amaranth. Filled symbols are from Expt. 1999, and open symbols are from Expt. 2000.

which is advantageous when grown under short and intermittent drought conditions. On the contrary, the higher sensitivity of stomata in response to soil drying in WS80-192 is likely to be a disadvantage under short, intermittent drought stress, since an early closure of stomata restricts $\mathrm{CO}_{2}$ uptake, and thus dry matter production (Jones, 1998). This is shown by the positive correlation between the relative reduction of DW and $\mathrm{C}_{\mathrm{S}}\left(\right.$ or $\mathrm{C}_{\mathrm{T}}$ ). On the other hand, drought stress of a long duration may favor WS80-192. By closing stomata early in the drying cycle, WS80-192 would conserve water in the soil and increase its chances of survival under prolonged drought stress.

In conclusion, the present investigation demonstrated that genotypic variation existed with respect to $\mathrm{C}_{\mathrm{S}}$ and $\mathrm{C}_{\mathrm{T}}$ in vegetable amaranths. The variation revealed differences in the strategies of amaranth genotypes to adapt to drought stress. This information should be important for selection of drought-resistant genotypes for production under diverse environments.

\section{Literature Cited}

Blum, A. 1996. Crop response to drought and the interpretation of adaptation. Plant Growth Regulat. 20:135-148.

Field, C. and H.A. Mooney. 1986. The photosynthetic-nitrogen relationship in wild plants, p. 25-33. In: T. Givnish (ed.). On the economy of plant form and function. Cambridge Univ. Press, Cambridge, U.K.

Hammer, G.L. and R.C. Muchow. 1990. Quantifying climatic risk to sorghum in Australia's semiarid tropics and subtropics: Model development and simulation, p. 205-232. In: R.C. Muchow and J.A. Bellamy (eds.). Climatic risk in crop production: Models and management for the semi-arid tropics and subtropics. C.A.B. Intl., Wallingford, U.K.

Jefferies, R.A. 1993. Response of potato to drought. I. Expansion of individual leaves and osmotic adjustment. Ann. Appl. Biol. 122:93-104.

Jensen, C.R., H. Svendsen, M.N. Andersen, and R. Lösch. 1993. Use of the root contact concept, an empirical leaf conductance model and pressure-volume curves in simulating crop water relations. Plant Soil 149:1-26.

Jensen, M.C. and J.E. Middleton. 1970. Scheduling irrigation from pan evaporation. Wash. Agr. Expt. Sta. Circ. 572.

Jones, H.G. 1992. Plants and microclimate: A quantitative approach to environmental plant physiology. 2nd ed. Cambridge Univ. Press, Cambridge, U.K.

Jones, H.G. 1998. Stomatal control of photosynthesis and transpiration. J. Expt. Bot. 49:387-398.

Kochler, M. 2000. Analyse und Modellierung der Anpassungsreaktionen von Blumenkohl (Brassica oleracea L. botrytis) an eine limitierte Wasserversorgung. PhD diss. Univ. of Hannover, Hannover, Germany.

Lecoeur, J. and T.R. Sinclair. 1996. Field pea transpiration and leaf growth in response to soil water deficits. Crop Sci. 36:331-335.

Liu, F. 2000. Adaptation of vegetable amaranth to drought stress. MS thesis. Univ. of Hannover, Hannover, Germany.

Martin, F.W. and R.M. Ruberte. 1975. Edible leaves of the tropics. Antillian College Press, Mayaguez, Puerto Rico.

Martin, F.W. and L. Telek. 1979. Vegetables for the hot, humid tropics. part 6. Amaranthus and Celosia. U.S. Dept. Agr., S. Reg. Agr. Res. Ser., Mayaguez, Puerto Rico.

Mclntyre, B.N.D., D.J. Flower, and S.J. Riha. 1993. Temperature and soil water status effects on radiation use and growth of pearl millet in a semi-arid environment. Agr. For. Meteorol. 66:211-227.

Milroy, S.P. and P.J. Goyne. 1995. Leaf area development in barley-Model construction and response to soil moisture status. Austral. J. Agr. Res. 46:845860.

Muchow, R. and T.R. Sinclair. 1991. Water deficit effects on maize yields modelled under current and "greenhouse" climates. Agron. J. 83:425-437.

Myers, R.L. 1996. Amaranth: New crop opportunity, p. 207-220. In: J. Janick (ed.). Progress in new crops. ASHS Press, Alexandria, Va.

Passioura, J.B. 1972. The effect of root geometry on the yield of wheat growing on stored water. Austral. J. Agr. Res. 23:745-752.

Ray, J.D. and T.R. Sinclair. 1997. Stomatal closure of maize hybrids in response to drying soil. Crop Sci. 37:803-807.

Ray, J.D. and T.R. Sinclair. 1998. The effect of pot size on growth and transpiration of maize and soybean during water deficit stress. J. Expt. Bot. 49:13811386.

Ritchie, J.T. 1981. Water dynamics in the soil-plant-atmosphere system. Plant Soil 58:81-96.

Robertson, M.J. and S. Fukai. 1994. Comparison between models for grain sorghum under continuous soil drying. Field Crops Res. 36:145-160.

Rosenthal, W.D., G.F. Arkin, P.J. Shouse, and W.R. Jordan. 1987. Water deficit effects on transpiration and leaf growth. Agron. J. 79:1019-1026.

Sadras, V.O. and S.P. Milroy. 1996. Soil-water thresholds for the responses of leaf expansion and gas exchange: A review. Field Crops Res. 47:253-266.

Sadras, V.O., F.J. Villalobos, and E. Fereres. 1993a. Leaf expansion in fieldgrown sunflower in response to soil and leaf water status. Agron. J. 85:564-570.

Sadras, V.O., F.J. Villalobos, E. Fereres, and D.W. Wolfe. 1993b. Leaf response to soil water deficits: Comparative sensitivity of leaf expansion rate and leaf conductance in field-grown sunflower (Helianthus annuus L.). Plant Soil 153:189-194.

Sage, R.F. and R.W. Pearcy. 1987. The nitrogen use efficiency of $\mathrm{C}_{3}$ and $\mathrm{C}_{4}$ plants. I. Leaf nitrogen, growth, and biomass partitioning in Chenopodium album $\mathrm{L}$. and Amaranthus retroflexus L. Plant Physiol. 84:954-958.

SAS Institute, Inc. 1998. SAS/STAT user's guide: Release 6.03 ed. SAS Inst., Inc., Cary, N.C.

Soltani, A., F.R. Khooie, K. Ghassemi-Golezani, and M. Moghaddam. 2000. Thresholds for chickpea leaf expansion and transpiration response to soil water deficit. Field Crops Res. 68:205-210.

Tardieu, F. and W.J. Davies. 1993. Integration of hydraulic and chemical signalling in the control of stomatal conductance and water status of droughted plants. Plant Cell Envrion. 16:341-349.

Turner, N.C. 1997. Further progress in crop water relations. Adv. Agron. 58:293338.

Turner, N.C. and M.E. Nicolas. 1987. Drought resistance of wheat for lighttexture soils in a Mediterranean climate, p. 203-246. In: J.P. Srivastava, E. Porceddu, E. Acevedo, and S. Varma (eds.). Drought tolerance in winter cereals. Wiley, New York.

Whitehead, W.F. and B.P. Singh. 1992. Vegetable amaranth performance at different soil moisture levels. HortScience 27:1176. 